der Aussprache lauten beide Ausdrücke völlig gleich: kakin gakos), so könnte das ein Produkt gelehrter Reflexion sein, wie sich Ähnliches für die moderne neugriech. Schriftsprache auch sonst nachweisen lälst.

Doch alle diese Fragen und Zweifel werden unsere Autoritäten auf dem Gebiete der mittelgriechischen Sprachforschung, denen durch

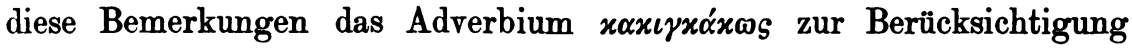
empfohlen werden soll, besser beantworten und entscheiden können.

Riga.

Ed. Kurtz.

\title{
Orientalisches im Byzantinischen.
}

\section{1. $\Sigma \alpha \beta \alpha x \alpha^{\prime} \vartheta \iota 0 \nu$.}

Dies Wort erklären Suidas u. A. durch бovớá@ıv, Hesych. durch

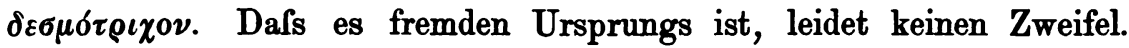
Nun stimmt dazu das syrische $s^{\ominus} b a ̂ k^{\mathrm{h}} \hat{a}$ (Judith $X$ 4). Dieses erklären die Glossographen (bei Payne Smith 2502) folgendermafsen: „etwas was Frauen auf ihren Kopf legen; es ist eine Art geflochtenes Netz und man nennt es auch sudartâ (aus бovớócov)". - Noch viel gebräuchlicher ist das Wort im Jüdisch-Aramäischen ("Ârûch s. v. סבכה), wo auch die besser zu $\sigma \alpha \beta \alpha x \alpha \sigma^{\prime} \iota \nu \nu$ stimmende Femininform o gangbar ist.

\section{2. 'A $A \alpha \nu \alpha^{\prime} \tau \eta$ (Duc. 56).}

Die Bedeutung "Sicherheit" steht fest. Es ist also das arabische - auch ins Türkische übergegangene - amânat "Sicherheit".

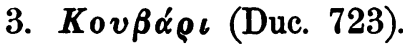

Das Wort wird als „Knäuel" erklärt. Im Griechischen scheint es keine Ableitung zu haben. Dagegen kennt das Aramäische $\mathbf{k}^{\bullet} \mathbf{b}^{\mathrm{h}} \mathrm{ârâ}$, kịbûûa als gebräuchliches Wort für „Knäuel“ (Löw, Aramäische Pflanzennamen S. 120). Doch scheint der griechischen Form eine andere (arabische?) Umbildung zu grunde zu liegen.

\section{Kó $\chi \lambda$ os (Duc. 749).}

In der Frauensprache für $\sigma \tau i \mu \mu \iota$ gebraucht. Es ist das arabische kuhl (syr. kuḥlâ) „stibium“.

\section{5. $\Phi_{\eta} \tau \iota \lambda \iota \nu$ (Duc. 1673).}

Das Wort geht am letzten Ende sicher auf arab. fatîla „Docht"

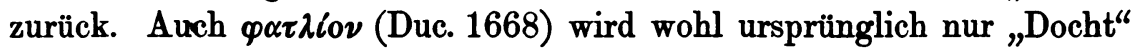
bedeutet haben.

\section{Pó $\mu \pi \lambda \iota$ ov (Duc. 1281).}

Als „libellus astronomicus seu mathematicus Persarum“ erklärt. Es ist ein Wahrsagebuch und gehört gewifs zum arabischen ramal „Geomantie“ (die Kunst aus verborgenen Zeichen, eigertlich aus Linieu im Sande - raml - zu wahrsagen).

Breslau.

Siegmund Fraenkel. 